\title{
Representação social da aposentadoria para professores universitários
}

\author{
Social representations of retirement for teachers at public universities
}

\author{
Luana de Barros Campos Amaral ${ }^{1}$ \\ Tatiana Lucena Torres ${ }^{2}$
}

\begin{abstract}
RESUMO: O objetivo do presente estudo foi analisar as representações sociais da aposentadoria para professores que trabalham em duas universidades federais do nordeste brasileiro. Foram realizadas vinte entrevistas narrativas, pareadas por sexo e instituição, com professores universitários que possuíam 50 anos ou mais de idade. As entrevistas transcritas foram analisadas com auxílio de software de análise textual, do tipo lexicográfica. Os resultados indicaram a composição de seis classes textuais e as representações sociais mais fortes se referiam à aposentadoria como nova etapa de vida, retorno à família, envelhecimento, viagens e lazer. Para os entrevistados, as representações sociais da aposentadoria foram positivas, no entanto, a perspectiva de um trabalho satisfatório, somado ao medo em relação às mudanças previdenciárias e a própria vida, reforçam a intenção de adiar a aposentadoria. Não houve diferenças significativas entre instituições, o que demonstra certa homogeneidade das representações para esse grupo profissional.
\end{abstract}

Palavras-chaves: aposentadoria; professores; representação social; universidade federal.

\begin{abstract}
This study aimed to analyze social representations of retirement among professors that work at two federal universities in northeastern Brazil. Twenty narrative interviews were carried out, paired by gender and institution, with university professors aged 50 and above. The transcribed interviews were analyzed with the aid of lexicographical text analysis software. The results indicated six text categories and the strongest social representations referred to retirement as a new phase in life, a return to family, aging, travel and leisure. For the interviewees, the social representations of retirement were positive, however, the prospect of a satisfactory job, added to the fear in relation to social security changes and life itself, reinforce the intention to postpone retirement. There were no significant differences between institutions, which demonstrates a certain homogeneity in representations among this professional group.
\end{abstract}

Keywords: retirement; professors; social representation; federal university.

\section{Introdução}

Este artigo pretende refletir sobre a representação social da aposentadoria para professores que trabalham em duas instituições públicas federais de ensino superior no nordeste brasileiro. Buscamos evidenciar no presente estudo, articulações entre as representações sociais da aposentadoria e as práticas de professores universitários, na tentativa de responder aos seguintes questionamentos: Como compreender as representações sociais da aposentadoria e seus impactos na vida do professor universitário? Como este fenômeno se apresenta no imaginário social dos participantes da pesquisa? Para que essa compreensão seja possível torna-se importante apresentar os conceitos de aposentadoria, assim como aspectos da teoria da representação social que respaldam o presente artigo.

\footnotetext{
${ }^{1}$ Psicóloga da Universidade Federal Rural de Pernambuco. Mestranda no Programa de Pós-Graduação da Universidade Federal do Rio Grande do Norte - Rio Grande do Norte, Brasil. E-mail: luaamaral@hotmail.com.

2 Professora do Programa de Pós-Graduação em Psicologia, Departamento de Psicologia, Universidade Federal do Rio Grande do Norte - Rio Grande do Norte, Brasil.
} 
A inversão da pirâmide populacional e o aumento na expectativa de vida é uma realidade documentada no último relatório técnico "Previsões sobre a população mundial", elaborado pela Organização das Nações Unidas (ONU) e no Relatório Mundial de envelhecimento e saúde (2015) da Organização Mundial de Saúde (OMS). Segundo as estimativas realizadas por institutos como o Instituto Brasileiro de Geografia e Estatística (IBGE) em 2025 teremos no Brasil, a quinta população mais velha do mundo (OMS, 2015; IBGE, 2013).

O aumento do número de idosos na população brasileira tem levado à questionamentos sobre o equilíbrio do sistema previdenciário, e consequentemente, na sustentabilidade da manutenção do direito à aposentadoria. Devido as suas transformações no decorrer da história e sua dinamicidade, definir aposentadoria é algo que perpassa por diferentes compreensões e representações. Segundo alguns autores, nenhuma definição abarca a complexidade desse fenômeno e as múltiplas facetas que o mesmo representa (Denton \& Spencer, 2009; Roesler \& Soares, 2010; Shultz \& Wang, 2011). Uma definição mais geral e bastante utilizada por pesquisadores é que aposentadoria é a saída remunerada do trabalho (Denton \& Spencer, 2009).

A identidade profissional é agenciada pelo social e a visão da aposentadoria, como a imersão na inatividade, faz com que até mesmo os velhos queiram continuar trabalhando, temendo o tempo como o fantasma de suas vidas (Stano, 2001). Requerer a aposentadoria oficial implica fazer escolhas. Para um aposentado é inevitável escolher entre algumas opções como, por exemplo, uma segunda carreira ou à continuidade da atuação profissional com diferentes vínculos. A aposentadoria representa uma interrupção nas atividades praticadas durante anos em uma determinada situação, por isso, não pode ser considerada simplesmente como término de uma carreira.

O processo da aposentadoria demanda equilíbrio emocional para não gerar sofrimento e perda da identidade social. Sobre esse momento incidem diferentes significados e representações. Ao deparar-se com essa problemática dentro de uma categoria profissional, percebe-se que há vários aspectos envolvidos dentro e fora desse grupo. Os professores universitários são exemplos de uma categoria profissional que tem atravessado mudanças institucionais que refletem nas imagens e identidades profissionais, se caracterizando pela contradição entre ser professor e cumprir as exigências de uma polivalência típica da atividade no ensino superior, que circula entre o ensino, pesquisa, extensão e gestão (Lima, 2012).

O papel social que o professor exerce faz com que o mesmo construa sua identidade dentro de um processo direto de identificação com o ofício, ao mesmo tempo em que o aumento da demanda de trabalho, prescrita com as reformas educacionais brasileiras, traz em seu dorso o descontentamento com esse ofício. Compreender o pensamento social sobre a aposentadoria para professores universitários implica em aproximar-se da prática social evidenciada pelo adiamento da aposentadoria e mesmo da rotineira perspectiva de que esses profissionais continuam trabalhando, mesmo depois de aposentados (Macêdo, Bendassolli \& Torres, 2017).

A análise de representações sociais tal como conceitua Moscovici (2012) é a possibilidade de categorização do conhecimento adquirido através da inserção sociohistórica, considerando a constituição do indivíduo como ser subjetivo. Sendo assim reconhecidas como a teoria do senso comum dentro de um determinado tempo e espaço. 
Moscovici (1978) destaca que o homem não absorve os conteúdos tais quais lhe são repassados. Ao contrário, os sujeitos os reformulam quando com eles se deparam. No processo de interação social, o sujeito elabora o conhecimento, vai se socializando, reconstruindo valores e ideias que circulam na sociedade. Essa reformulação ocorre principalmente devido ao fato de o indivíduo ser ativo e não meramente passivo diante do mundo. Jodelet (2001) afirma que as representações sociais nos guiam na maneira de nomear e definir em conjunto os diferentes aspectos da realidade cotidiana. É um movimento entre o indivíduo e o social que busca trazer para o mundo familiar àquilo que é estranho no primeiro contato. A mesma autora define a representação social como "uma modalidade de conhecimento, socialmente elaborada e partilhada, com um objetivo prático e contribuindo para a construção de uma realidade comum a um conjunto social" (p. 36).

A apropriação do conhecimento científico pelo senso comum acontece através de dois processos sociocognitivos intrinsecamente ligados: a objetivação e a ancoragem. A ancoragem e objetivação são maneiras de lidar com a memória e comunicar-se com o mundo. A ancoragem mantém a memória em movimento, a qual é dirigida para dentro e está sempre armazenando e excluindo objetos, pessoas e acontecimentos classificados e nomeados por essa ancoragem de acordo com os seus tipos. A objetivação, mais ou menos direcionada para fora (para outros), elabora conceitos e imagens para reproduzi-los no mundo exterior ().

Essa pesquisa teve como objetivo analisar as representações sociais da aposentadoria para professores universitários com mais de 50 anos, que atuam em instituições públicas federais, destacando como as modificações sociais vêm trazendo alterações nas representações sociais desses sujeitos que estão próximos a aposentadoria, mas continuam trabalhando.

\section{Método}

Trata-se de um estudo descritivo de caráter predominantemente qualitativo, que utilizou entrevistas narrativas individuais, que versaram sobre: o tema da aposentadoria, suas representações e medos, assim como o transcorrer da história de vida profissional. No que diz respeito aos procedimentos éticos, o presente estudo primou pelo sigilo e participação voluntária dos entrevistados, solicitou autorização para gravação de voz e para utilização das informações para fins de pesquisa. Além disso, o estudo foi submetido e aprovado pelo Comitê de Ética em pesquisas com seres humanos.

\section{Participantes}

Foram entrevistados 20 docentes, sendo 10 na instituição do Rio Grande do Norte (RN) e 10 na instituição de Pernambuco (PE). As instituições foram escolhidas por critério de conveniência. A pesquisa teve como critérios de inclusão dos participantes, os professores ativos, com vínculo de contrato permanente dentro das cargas horárias de dedicação exclusiva e 40 horas e que possuíssem no mínimo 50 anos de idade. Esses critérios foram adotados visando atingir uma diversidade no que concerne ao tempo de atuação como professores e a proximidade com a aposentadoria. A aceitação de participação se deu através decisão expressa no questionário que foi disponibilizado online anteriormente, mas que não foi foco do presente estudo. 
Os entrevistados se dividiram equitativamente por universidade. Na instituição de PE foram entrevistadas seis mulheres e quatro homens e na instituição do RN, seis homens e quatro mulheres, totalizando um grupo paritário quanto ao sexo do participante. Além disso, os professores entrevistados se distribuíram em diferentes áreas de atuação, de modo que evitamos entrevistar mais do que duas pessoas de um mesmo departamento ou curso. As características sociodemográficas dos participantes estão descritas na tabela 1 , onde é possível identificar um perfil de pessoas casadas, que moram com cônjuge e filhos.

Tabela 1 - Características sociodemográficas dos participantes.

\begin{tabular}{lll}
\hline Variáveis de Caracterização & & Frequência \\
\hline Conjugalidade & Solteiro (a) & 5 \\
& Casado(a) & 12 \\
& União estável & 1 \\
& Viúva & 1 \\
& Separado ou divorciado(a) & 1 \\
\hline Total & & $\mathbf{2 0}$ \\
\hline Moradia & Cônjuge & 6 \\
& Cônjuge e filhos & 6 \\
& Sozinho(a) & 5 \\
& Pais (pai e/ou mãe) & 2 \\
\hline Total & Outros (filhos, parentes ou outras pessoas) & 1 \\
\hline
\end{tabular}

A tabela 2 demonstra como estão divididos os professores, levando em consideração o tempo de serviço e de instituição, além da participação em programas de pós-graduação. No delineamento laboral $90 \%$ dos entrevistados estão dentro do regime de dedicação exclusiva.

Foram entrevistados docentes com e sem cargos de chefias e/ou coordenações, na tentativa de compreender como as funções de gestão se enquadram nas funções de docentes. Outra variável que não destacamos nas entrevistas, mas que ocorreu com a população entrevistada é que alguns dos desses entrevistados já estão aptos a se aposentar e recebem a gratificação de abono permanência por continuarem trabalhando.

Tabela 2 - Características sociolaborais dos participantes.

\begin{tabular}{lll}
\hline Variáveis de Caracterização & & Frequência \\
\hline Tempo de serviço & De 20 a 30 anos & 9 \\
& De 31 a 40 anos & 9 \\
& Mais de 40 anos & 2 \\
\hline Total & & $\mathbf{2 0}$ \\
\hline Tempo na Instituição & De 1 a 5 anos & 1 \\
& De 6 a 10 anos & 2 \\
& De 11 a 15 anos & 1 \\
& De 16 a 20 anos & 2 \\
& De 21 a 25 anos & 5 \\
& De 26 a 30 anos & \\
& De 31 a 35 anos & \\
\hline Total & Mais de 36 anos & $\mathbf{2 0}$ \\
\hline Professor de pós-graduação & Sim & 12 \\
\hline Total & Não & $\mathbf{2 0}$ \\
\hline
\end{tabular}




\section{Análise dos dados}

Os textos advindos da transcrição das entrevistas constituíram um corpus que foi analisado por meio de técnicas quantitativas de tratamento com auxílio do software IRAMUTEQ - Interface de $R$ Pour Analyses Multidimensionnelles de Textes et de Questionnaires (Nascimento \& Menandro, 2006; Camargo \& Justo, 2013). O IRAMUTEQ possibilitou analisar a coocorrência de palavras nos segmentos dos textos dos discursos, elaborando uma Classificação Hierárquica Descendente (CHD) apresentada na forma de um dendograma, indicando em classes lexicais os eixos dos discursos e uma Análise Fatorial por Correspondência ( $A F C$ ) permitindo visualizar, sob a configuração de um plano fatorial, as oposições resultantes da CHD (Mutombo, 2013). As classes lexicais foram constituídas das palavras com o maior grau de significância em relação à classe e seus respectivos percentuais de segmentos de textos onde apareceram, em relação ao total do corpus da análise. Esse tipo de tratamento permitiu identificar discursos distintos a respeito do objeto, bem como analisar as inter-relações entre eles.

A escolha da análise utilizada se justificou pelo número de informações obtidas e também por possibilitar explorar associações e relações entre os dados textuais e as variáveis selecionadas no instrumento. Foram utilizados critérios simultâneos como ponto de corte para inclusão de elementos no dendograma: a frequência das palavras (maior ou igual à média de ocorrências ou com $100 \%$ de porcentagem na classe), e o qui-quadrado $X^{2}$ (1) $\geq 3,84$ com nível de significância de $p<0,05$.

\section{Resultados}

O corpus analisado foi denominado Representação Social da Aposentadoria e foi constituído por 20 respostas às questões: "O que representa a aposentadoria para você? E quais são seus medos em relação a essa fase?". Este corpus obteve 11.612 ocorrências de palavras, sendo 1.915 formas distintas, com frequência média de aproximadamente seis palavras $(6,1)$ para cada forma, sendo esse o critério utilizado como ponto de corte para inclusão de palavras no dendograma. Esse corpus foi dividido em 335 segmentos de texto, e, destas, 298 , ou seja, $88,96 \%$ do total de palavras foram equiparadas. Com relação ao número de palavras únicas (denominado hapax no Iramuteq), 619 apresentaram essa característica, correspondendo 5,33\% das ocorrências de palavras.

O dendograma se dividiu em seis classes distintas, subdivididas em partições. No primeiro momento duas grandes partições surgiram e essas por sua vez se desdobraram em outras partições gerando subclasses. Observando o dendograma (Figura 1) da esquerda para direita e de baixo para cima, é possível perceber que na primeira partição, se gera uma subpartição com as classes 1 e 2 e outra partição que origina a classe 6 e mais uma partição que origina a classe 5 e uma subpartição com as classes 3 e 4. 


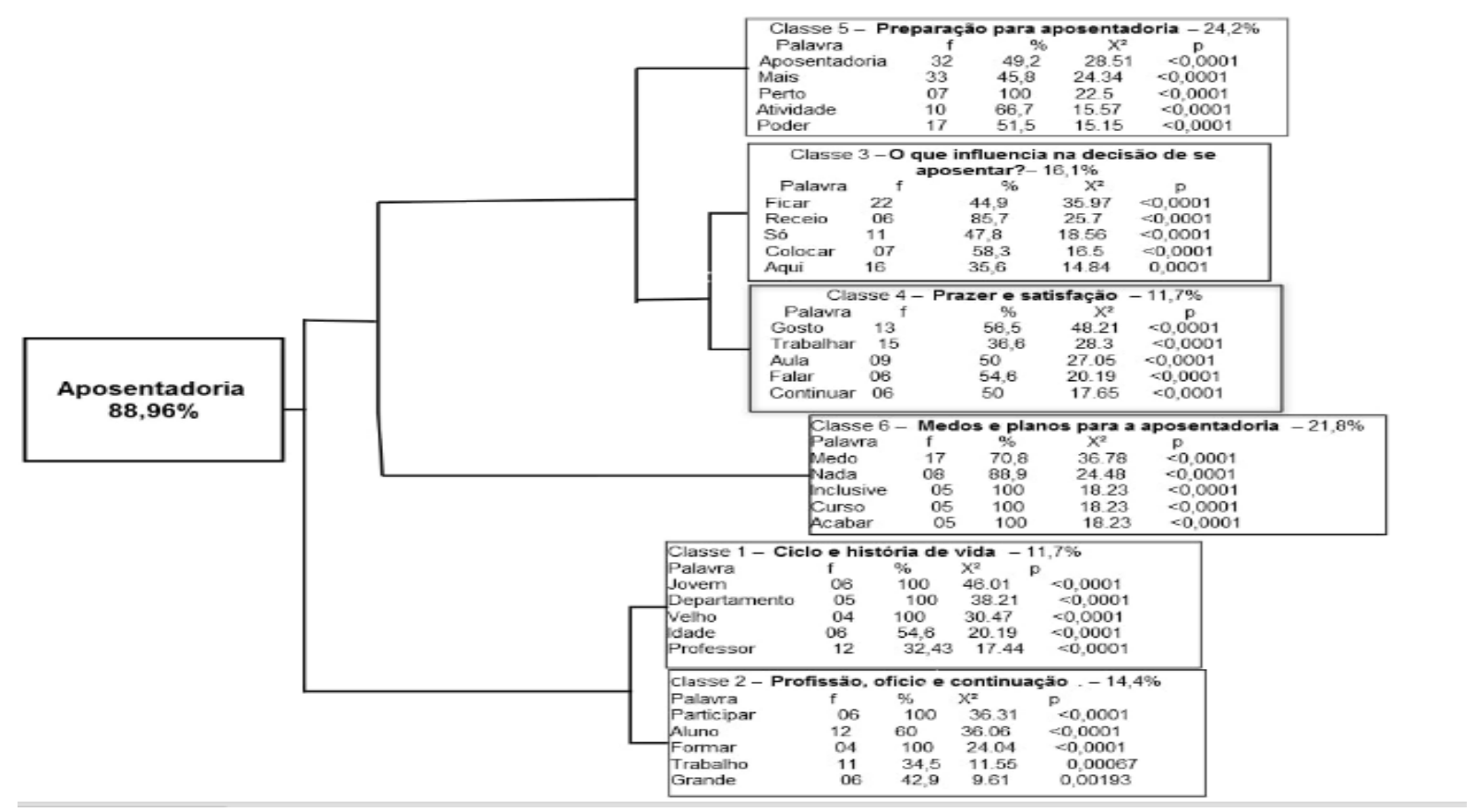

Figura 1 - Dendograma Aposentadoria

Pela figura 1 podemos perceber que a Classe 1 e 2 que se originam na primeira subpartição se encontram em oposição em relação a todas as outras classes. Já a classe 6, que também se origina da primeira grande partição, enquanto que a partição que deram origem as classes 5, 4 e 3 concentram o maior número de segmentos de textos.

A primeira classe denominada "ciclo e história de vida", ela explicou 11,7\% do corpus. Esta classe foi assim denominada por suas palavras significativas remeterem ao processo de envelhecimento, o ciclo da vida e história profissional. A partir dessa classe, foi possível inferir que a constituição da identidade do professor extrapola a prática laboral. Nessa classe percebe-se que quando se pensa em aposentadoria voluntária, pensa-se também em idade e ciclo de vida.

As palavras mais significativas dessa classe remetem ao processo de envelhecimento e como os temas aposentadoria e docência são percebidos por esses professores. Colaboraram significativamente para a construção dessa classe as pessoas que trabalham na instituição na faixa temporal de 31 a 35 anos. Para o melhor conhecimento da classe destacamos alguns trechos evidenciados nesta divisão.

... eu acho que a aposentadoria, como a maioria se aposenta com uma certa idade, tem a ver com a velhice e a gente pensa aposentadoria, lembra logo de velho, de gente que não consegue se locomover... (e_17; mulher; RN; solteira; mora sozinha; de 6 a 10 anos de instituição; 30 a 40 anos de tempo de serviço, não é professora da pós-graduação; D.E).

... Tenho um pouco de medo do envelhecimento, mas até agora me sinto jovem. Acho que o contato com a juventude rejuvenesce a gente... Mas, os jovens precisam de oportunidades, fazem toda a formação e não podem atuar porque não queremos dar espaço, estou pensando que isso é um limitador, mas é importante fazer... (E_19; homem; RN; casado; mora com cônjuge; de 31 a 35 anos de instituição; de 30 a 40 anos de serviço; não é professor de pós-graduação; D.E).

A classe 2 , que divide esse primeiro eixo, tem $14,4 \%$ do corpus e foi denominada "profissão, ofício e continuação", por trazer fortemente a ideia de continuidade de trabalho, sobre as condições de trabalho dentro da universidade, assim como o ofício e identidade que não se perde com a aposentadoria. 
Nesta classe, a categoria de variáveis que contribuíram de forma mais significativa foram: regime de trabalho 40 horas (carga-horária), homens (sexo), pessoas com mais de 40 anos de serviço (tempo de trabalho). Outras categorias de variáveis significativas foram: os tempos institucionais nas faixas de mais de 36 anos e de 1 a 5 anos (idade), pessoas casadas (situação conjugal), que moram com cônjuges e filhos (moradia).

Para melhor exemplificar esta classe, foram selecionados alguns trechos das entrevistas que ajudam na compreensão do contexto.

... eu gosto de ensinar, eu gosto de estudar, eu gosto de aprender, embora a universidade hoje, os alunos de hoje, devido aos recursos que eles têm e que deveriam usar a favor deles, eles usam contra eles... Eu faço pelo aluno, o aluno reclama muito da prática e o que eu faço exatamente é criar oportunidades para que eles pratiquem (E_02; homem; RN; casado; mora com cônjuge e filho (s); mais de 36 anos de instituição; mais de 40 anos de serviço; não é professor de pósgraduação, 40h.).

... Mas dadas às condições, as próprias condições de trabalho que não mudaram, não mudam, você por mais que cresça, por mais que você faça alguma coisa, você percebe que o problema é muito mais amplo e bem maior que você... Nem o próprio local que você está lotado ele interfere, isso é uma grande riqueza do trabalho do professor de terceiro grau, porque todo recurso para eu desenvolver minha pesquisa eu posso trazer de fora... (E_14; homem, PE; solteiro; mora sozinho; tempo de instituição 21 a 25 anos, tempo de serviço 20 a 30 anos; professor de pós-graduação; D.E.).

Na partição oposta, como é possível ver pelo dendograma, a classe que primeiro se destaca é a seis, ela tem $21,8 \%$ do corpus e foi denominada "medos e planos para a aposentadoria" porque as suas palavras e contextos remetem aos medos e desafios que esta nova etapa traz, além da perspectiva de continuidade ou mudança.

É importante ressaltar que nesta classe, muitas palavras apresentaram frequência abaixo da frequência média calculada, mas que compuseram percentagem total nessa classe, o que a torna bem caracterizada. As categorias de variáveis significativas que ajudaram na construção da classe foram: mulheres, pessoas que moram sozinhas, tempo de instituição entre 6 e 10 anos. E para melhor exemplificar essa classe, alguns trechos foram selecionados:

... Quer dizer, não devia ter se aposentado, eu vejo com olhos muito negativos, principalmente quem resolve se aposentar novo, meu pai acabou se aposentando novo foi uma besteira, meu tio voltou a trabalhar inclusive em empresa... A pessoa também se sente menos útil, em geral, as pessoas caem em depressão, ficam doentes e acabam tentando achar uma outra coisa pra fazer... Eu não gosto de serviço de casa, de nada disso, vou continuar dando algumas aulas ou vou para iniciativa privada... (E_17; mulher; RN; solteira; mora sozinha; tempo de instituição entre 6 e 10 anos; tempo de serviço entre 30 e 40 anos; não é professor de pós-graduação; D.E.).

... Mesmo que ele esteja agora trabalhando em faculdades particulares, mas ele não se sente mais aquele professor que era do curso médico, porque o reconhecimento acabou, ele está aposentado... No momento que você representa um cargo e passa a se aposentar, ah professora aposentou, então dali por diante, é como se você não tivesse mais o conhecimento, não tivesse mais a posse, não tivesse mais nada... De saber que você não manda em nada, tudo são parcerias, é o medo da aposentadoria eu acho do não fazer nada... (E_07; mulher; PE; casada; mora com cônjuge; tempo de instituição entre 21 e 25 anos; tempo de serviço de 20 a 30 anos; professor de pós-graduação, D.E.).

A terceira partição do dendograma dá origem a classe 5 e a bipartição dessa às classes 3 e 4 . A quinta classe se destaca nessa subpartição e por se caracterizar como a maior classe formada dentro do corpus, correspondendo a $24,2 \%$ deste. 
A classe 5 foi denominada de "preparação para aposentadoria", porque nela o sentido que mais se destaca é o planejamento para a mesma, as possibilidades de lidar com esse momento que está chegando ou mesmo que já está sendo adiado por alguns. Ser professor de pós-graduação foi a categoria que mais contribuiu para a formação dessa classe. Para melhor exemplificar a classe, alguns trechos das entrevistas se destacaram:

\begin{abstract}
... Aposentadoria representa mais uma fase da vida, essa fase da vida ela tem que ser bem pensada, por quê? (...) Na realidade eu estou no estado de permanência, ou seja, eu já cumpri todo o meu tempo para aposentadoria, eu não sei se você sabe, mas a universidade, ela paga aquilo que descontava para gente continuar na universidade... Mas enfim, eu não me vejo afastado da academia, não eu não considero a aposentadoria nem negativa nem positiva porque, por exemplo, positivo certamente que não é, porque eu não sairia da universidade nunca... (E_18; homem; PE; casado; mora com cônjuge e filho(s); tempo de instituição mais de 36 anos, tempo de serviço entre 30 e 40 anos, professor de pós-graduação, D.E.).

... O único planejamento que eu tenho é ganhar na mega-sena, estou brincando, não eu não tenho um planejamento para aposentadoria, porque embora eu já tenha idade e esteja completando tempo esse ano... Eu já estou no tempo de $80 \%$, então para eu ter $80 \%$ da minha aposentadoria eu tenho que esperar pelo menos até 2019... Aposentadoria para mim é o meu para sempre, o tempo que será meu e que terei que me projetar para mim... (E_15; mulher; RN; solteira; mora sozinha; tempo de instituição entre 11 e 15 anos; tempo de serviço de 20 a 30 anos; professor de pós-graduação; D.E.).
\end{abstract}

A última partição deu origem as classes 3 e 4 e estas se encontram em oposição dividindo o mesmo eixo. A classe 3 foi denominada "Aposentadoria e solidão" E tem 16,1\% do corpus total. Ela remete ao medo das mudanças, "do vazio" e solidão que a quebra do vínculo institucional pode representar.

As categorias de variáveis que mais influenciaram esta classe foram: tempo de instituição na faixa temporal de 11 a 15 anos e professores que não atuam na pósgraduação. Para melhor exemplificar esta classe, alguns trechos ilustrativos das entrevistas foram selecionados:

... Não, eu não quero mais isso para minha vida, se eu não fiquei rica até agora, não vou enricar mais, estou trabalhando, mas não é essa a pretensão... A velhice não, a velhice é inevitável, acho que a gente tem maturidade para encarar as mudanças no corpo, realmente a gente não fica mais bonita, eu não acho e pronto é isso... Você chega a essa altura da vida com um companheiro, um cúmplice, um amigo parceiro, um irmão, é tudo nesse sentido aí, eu tenho receio da viuvez, de ficar sozinha porque daí meus planos vão ficar bem defasados... (E_10; mulher; PE; casada; mora com cônjuge; tempo de instituição entre 1 e 5 anos; tempo de serviço entre 30 e 40 anos; não é professora de pós-graduação; D.E.).

A quarta classe corresponde a apenas $11,7 \%$ do corpus e foi denominada "trabalho e relação social", já que dentro dela foram encontrados os motivos para o trabalho e a aposentadoria serem prazerosos e constituidores de satisfação pessoal.

As categorias de variáveis que mais influenciaram na constituição dessa classe foram: tempo de instituição na faixa de 11 a 15 anos, mulheres solteiras. Para melhor exemplificar o contexto dessas palavras, alguns trechos foram considerados mais representativos:

... Gosto de planta, nunca mais tive planta porque não tenho tempo de cuidar. Eu na verdade não tenho medo não, de jeito nenhum, eu amo trabalhar, eu já disse... Embora eu tenha toda uma responsabilidade, eu sou uma pessoa que gosto muito de ser dona de casa, eu não tenho sido dona de casa no sentido de manter minhas coisas limpas, organizadas... (E_12; mulher; RN; casada; mora com cônjuge e filho(s); tempo de instituição entre 11 e 15 anos; tempo de serviço de 20 a 30 anos; não é professora da pós-graduação; D.E.). 
... porque eu gosto muito, me dá muito prazer trabalhar, eu acho se eu tiver condição física e mental eu vou continuar o tipo de atividade até os últimos dias.... Trabalhar com meio ambiente, com gente, não é um emprego é uma decisão de vida, é diferente. A aposentadoria vai me dar a possibilidade de ser remunerada por alguém e continuar a fazer o que eu gosto de fazer (...) (E_20; mulher; PE; viúva; mora com outras pessoas; tempo de instituição entre 26 a 30 anos; tempo de serviço entre 20 e 30 anos; não é professora de pós-graduação; D.E.).

Para uma análise geral de como as palavras se relacionaram e se conectaram, uma análise de similitude foi realizada, levando em consideração o triplo da frequência mínima (6) para compreender como os elementos da representação social da aposentadoria se relacionaram. A figura 2 demonstra as conexões entre os elementos representacionais.

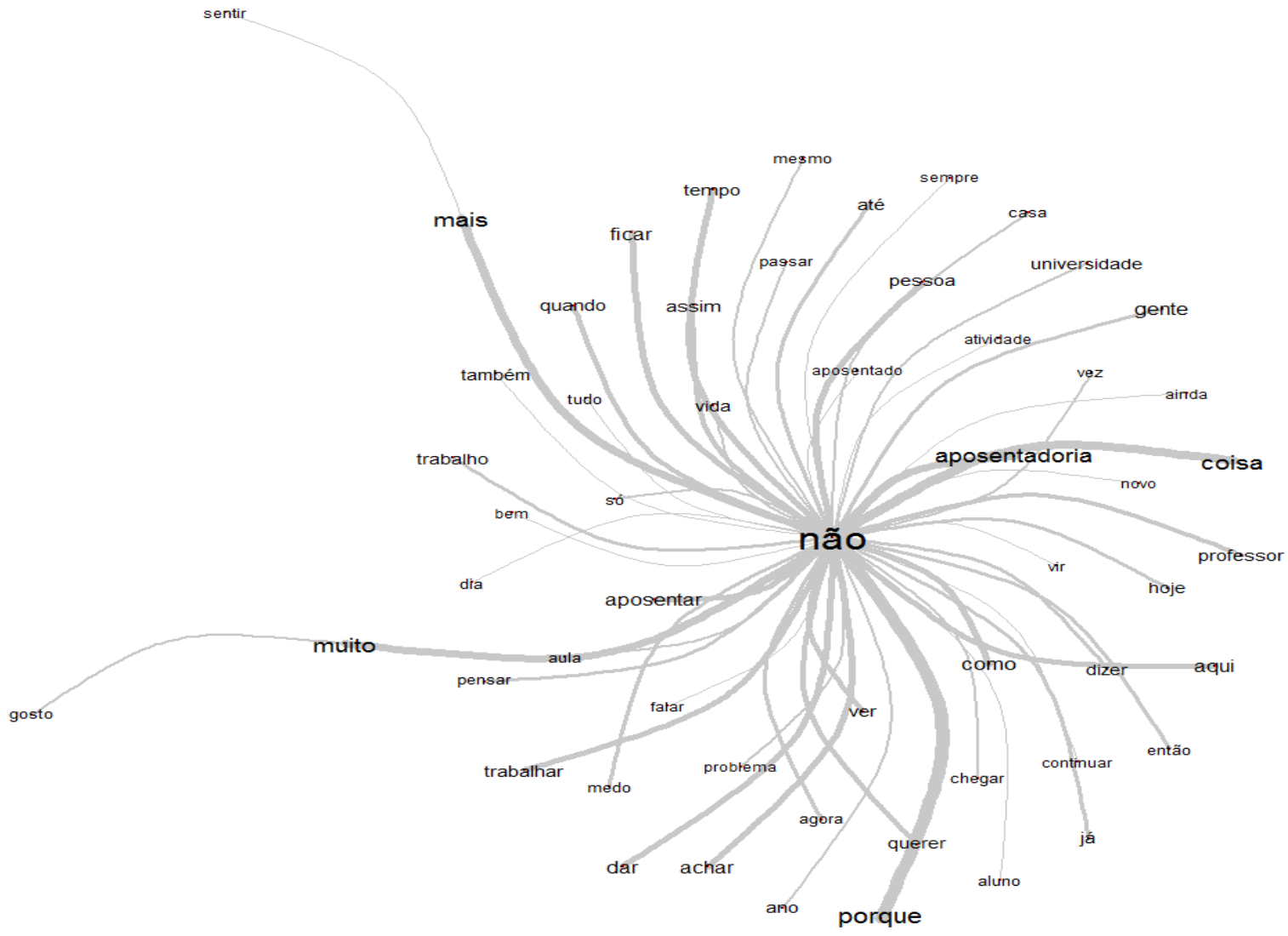

Figura 2 - Árvore de similitude Aposentadoria.

A árvore de similitude mostra que a palavra organizadora foi o "não", que nos contextos das entrevistas tinha sentido de negação, afirmação de um pensamento ou impedimento. As representações sociais da aposentadoria mostram que quando se tem uma atividade satisfatória no trabalho ou identificação profunda com a profissão, há um desejo de adiar a aposentadoria, mesmo que esta seja caracterizada de forma mais positiva do que negativa. Inferimos que o "não" organizou todos os elementos do conteúdo das falas dos entrevistados, porque persiste uma negativa em relação à ação de aposentar-se. Por outro lado, mostram que os impedimentos no trabalho geram uma reavaliação da possibilidade de aposentadoria, oferecendo subsídios para uma avaliação do objeto social aposentadoria a partir do fenômeno trabalho. 


\section{Discussão}

Para uma melhor compreensão das discussões, essa parte foi organizada tomando como base os ganhos e perdas percebidos pelos docentes dentro das representações sociais da aposentadoria e como o trabalho se relaciona com essas representações. Identificamos que para os participantes, trabalho e aposentadoria por mais que pareçam termos contrastantes, se complementam, porque a representação que se faz de um, remete as expectativas e crenças que se tem do outro, são aspectos que se retroalimentam.

De forma geral a aposentadoria foi representada de forma positiva, mostrando a centralidade de um novo começo, do retorno ao lar, às concepções de tempo para lazer e para fazer aquilo que não se teve tempo devido à rotina do trabalho.

Corroborando com a pesquisa de Macêdo (2014) e Menezes e França (2013) que constataram que as relações familiares influenciam diretamente na decisão de se aposentar e na concepção de uma aposentadoria melhor, para os docentes entrevistados no presente estudo, a aposentadoria foi representada pela possibilidade de liberdade, de fazer aquilo que se tem vontade ou até mesmo de retomar atividades abandonadas devido escolhas e necessidades da vida. O envolvimento com o trabalho também ressoa na representação da aposentadoria como direito conquistado, mas que pode ser adiado ao máximo para não se desligar do trabalho formal. Há ainda uma diferença entre se aposentar e deixar de trabalhar, percebendo o trabalho como condição humana de existência.

Entre os entrevistados há uma tendência em perceber de forma positiva o futuro que aguarda a decisão de se aposentar, mas de forma contraditória, optam por não se aposentar, mesmo com as modificações do mundo do trabalho (precarização, acúmulo de atividades, desvalorização da docência). Tal fato se caracteriza como reflexo do momento histórico vivido, uma vez que no momento das entrevistas (2015-2016) os debates sobre a Reforma da Previdência ainda não tinham sido pronunciados e não assumiam a visibilidade midiática que esse tema alcança atualmente.

Quando resgatamos os medos e receios com aposentadoria, esta se apresenta de forma mais negativa, estão no núcleo dessas representações: o medo do adoecimento, do ócio e as perdas trazidas com a velhice. É importante destacar que estes medos se fizeram mais presentes nas mulheres e nas pessoas solteiras ou viúvas sem filho, o que nos remete a pensar no medo do desamparo da sociedade e do isolamento. Mesmo diante da longevidade, aumento da expectativa de vida e da permanência em atividades laborais por mais tempo, o envelhecimento ainda se configura como um motivo para exclusão social (Bosi, 1994), onde o trabalhador mais velho é considerado uma força de trabalho obsoleta (Stano, 2001).

É importante ressaltar que o tempo ainda é o marcador institucional do ritmo da atividade social, ou seja, a vivência do tempo dentro de uma cronicidade, modulada pelas experiências vividas dentro do trabalho e fora dele, numa construção subjetiva e objetiva possibilitam que o sujeito traga para o mundo conhecido através de crenças e percepções aquilo que ainda não é vivido, mas pode vir a ser. Nesse sentido, a aposentadoria é representada pela quebra de um ritmo e a "desinstitucionalização do tempo", ou seja, a liberdade. Mas essas quebras podem refletir diretamente na identidade de trabalhador e, por isso, muitas vezes, esse momento é adiado de diferentes formas (França, 2004, 2008, 2009; Stano, 2001; Zanelli, Silva \& Soares, 2010). 
A aposentadoria é representada tanto pela liberdade quanto pela crise do papel do sujeito e de suas funções no mundo. Muitas vezes os docentes pesquisados falaram na continuação do trabalho através de outros vínculos profissionais com a mesma instituição, como professor convidado ou voluntário, ou até mesmo dando aulas em faculdades particulares. Esses meios mencionados apontam outra tendência quando se pensa nesse processo de transição entre trabalho e aposentadoria, o bridge employment, que pode ser visto como trabalhos que servem de transição entre o emprego e a aposentadoria completa, que são caracterizados pelo vínculo de continuação institucional, autoemprego (assessorias), trabalhos voluntários ou vínculos empregatícios mais flexíveis. (França, 2009; Menezes \& França, 2012; Menezes, Bendassolli \& Macêdo, 2013).

A continuidade de trabalho pode estar associada a fatores externos, como as políticas sociais e econômicas que interferem diretamente nas condições materiais da aposentadoria, ou internas, como a identificação positiva com o trabalho, condições de trabalho, percepção de autonomia e liberdade, pressão e disputas internas e apoio da família. Autores como Zanelli, Silva e Soares (2010); França (2002, 2009); França, Menezes e Siqueira (2012); defendem a necessidade de um planejamento prévio para este momento, de modo que as próprias instituições deveriam ter no seu hall de programas de capacitação de servidores, cursos voltados para este momento da vida. Embora as duas universidades pesquisadas possuam Programas de Preparação para Aposentadoria (PPA) já consolidados, poucos dos docentes participantes desse estudo realizaram tais cursos, o que deixa inviável uma inferência sobre como o curso interfere na representação social da aposentadoria, mas outros estudos poderiam se debruçar sobre essa temática.

O prolongamento da expectativa de vida e o consequente crescimento numérico da população de idosos coincidem com a inadimplência de alguns sistemas de previdência. Objetivados em interpretações econômicas neoliberais, alguns países propõem reformas estruturais nos sistemas de aposentadoria que impõem novas regras que obstaculizam o processo de seguridade social, à exemplo do que ocorre também no Brasil (Carlos, Jacques, Larratéa \& Heredia, 1999, p. 79).

Destacamos essas mudanças, porque elas incidem sobre os participantes com menos de 10 anos de instituição e porque essa problemática foi trazida por eles. Primeiro como uma forma de adiamento da aposentadoria, devido às perdas financeiras, e depois, como um desamparo institucional e das políticas públicas, uma vez que o envelhecimento traz a necessidade de investimentos maiores, especialmente em saúde. Para Veloz, NascimentoSchulze e Camargo (1999) o envelhecimento é representado como uma fase de nãotrabalho, refletindo a crença de que a aposentadoria significa o começo do desengajamento social. Isto ocorre, principalmente, pela valorização do trabalho como um patrimônio da juventude.

Estudos de representações sociais da aposentadoria indicam que esta é representada de forma positiva tanto para trabalhadores como para aposentados, embora os aposentados também apresentem uma visão mais negativa por já viver essa situação (Magalhães, Krieger, Groff et al, 2004; Costa, Barbosa \& Vilas Boas, 2012; Macêdo, Bendassolli \& Torres, 2017). Nas análises realizadas no nosso estudo, percebemos fortemente a vontade de não parar de trabalhar, do adiamento da aposentadoria, mesmo diante da perspectiva de "um descanso merecido", os participantes colocam os entraves para adiar a aposentadoria no momento que o direito for conquistado ou justificam a continuidade quando já existe a gratificação pela permanência, fato que estimula o adiamento da aposentadoria, mas que diante de sua 
extinção poderia atuar em sentido contrário, estimulando a finalização do vínculo com o trabalho. A aposentadoria também é vista como a possiblidade de trabalhar com mais autonomia e liberdade, no entanto, para a maioria dos professores participantes desse estudo, há autonomia no exercício do seu trabalho dentro da universidade, não se caracterizando, portanto, como um ganho direto da aposentadoria.

É importante ressaltar que essa posição de continuidade foi defendida pelos homens, e embora não tenhamos nos aprofundado nas questões de gênero, identificamos diferenças nas posições diante da aposentadoria. Achamos importante destacar algumas representações sociais que aparecem mais fortemente dentro dos gêneros, por compreender que estas diferentes posições interferem na análise realizada. Uma vez que as pessoas assumem diferentes funções sociais que se misturam com a docência que interferem nessa constituição da identidade docente.

Essa questão leva a refletir sobre a representação social da aposentadoria como o "retorno a família". A literatura aponta que essa volta do aposentado ao ambiente familiar difere em relação ao gênero (França, 2002). Em relação aos homens a maior convivência familiar pode parecer mais estressante, caso o mesmo não tenha uma participação ativa em casa. As mulheres por uma constituição histórica e cultural de acumular funções percebem de forma mais positiva e menos problemática esse retorno. Seria o "tempo de cuidar melhor da casa", "se dedicar a filhos e netos", "namorar", ter "planos com o cônjuge". França e Sandoval (2014) alertam que "se o arranjo na divisão de tarefas domésticas entre o casal não for efetivado ao longo do relacionamento, será muito difícil o compartilhamento do homem e mulher em situação de igualdade na aposentadoria" (p. 155). Os homens brasileiros quando pensam na divisão do tempo na aposentadoria, geralmente não inserem as tarefas domésticas como atividades a serem desenvolvidas no futuro, já que não as desempenham no presente. (França, 2004, 2008).

A família aparece como algo a se dedicar, por ter mais tempo. Essa perspectiva abrange a realidade de ter que lidar com diferentes gerações, os filhos crescidos que constituem novas famílias, a chegada dos netos e os pais envelhecidos aparecem como demanda a ser atendida com a aposentadoria. Expressões como "cuidar dos negócios dos meus filhos", "ajudar na educação dos meus netos", "ter mais tempo para a minha esposa", "cuidar da minha mãe", "ir morar próximo aos meus filhos", "Ainda tenho pais vivos e quero cuidar melhor deles", trazem essa dimensão de retorno à família. Na mesma direção, alguns autores apresentam a importância dos laços familiares para o estabelecimento de uma aposentadoria satisfatória e de uma velhice bem-sucedida (Bressan, Mafra, França, Melo \& Loretto, 2013; França, 2004, 2008; França \& Carneiro, 2009; França, Menezes \& Siqueira, 2012;).

Outro aspecto importante da representação social da aposentadoria diz respeito à dependência econômica e social que os docentes desempenham na família. Todos os participantes revelaram que são a renda principal do núcleo familiar, o que nos promove uma reflexão sobre a liberdade de escolha em relação ao momento de se aposentar quando o professor é o principal provedor da família.

Além da dimensão financeira, há também um papel intergeracional de generatividade (passar a história e memória para os mais novos), permeados por laços afetivos, tão importantes para a construção da identidade e sentimento de pertença. Esse papel se estabelece tanto na família quanto no trabalho (França \& Sandoval, 2014). 
Outra dimensão da representação social que se destaca é o lazer e viagens. Que aparecem como termos centrais. O tempo é visto como algo a ser preenchido de forma gratificante. Essas representações corroboram com as pesquisas que indicam que no primeiro momento a aposentadoria é vista como "férias eternas", momento de descanso e ócio. Mas as pesquisas demonstram também que com o tempo essa dimensão tende a desaparecer, considerando a situação econômica e social dos aposentados. Sendo muitas vezes substituídas pela sensação de liberdade ou necessidade de reinserção no mercado de trabalho (França, 1999; Cintra \& Ribeiro, 2009; Costa, Barbosa \& Vila Boas, 2012).

Parece evidente que as representações sociais positivas da aposentadoria revelam certa "ilusão" em relação ao cotidiano de uma pessoa aposentada, e, além disso, uma perspectiva de certa forma cruel, de que se pode esperar para "viver depois" quando a aposentadoria chegar! De modo geral as representações sociais da aposentadoria para os docentes com 50 anos ou mais, que trabalham nas universidades públicas federais pesquisadas foram positivas, por isso, podemos inferir que esta é vista como uma nova etapa da vida que é desejada e na qual se espera conviver mais com a família e aproveitar o tempo de uma nova forma com outras atividades e com mais atividades prazerosas e cuidados com a saúde, buscando também um envelhecimento bem-sucedido. Dialogando com a pesquisa de Liberatti et. al (2015) sobre as Representações Sociais da aposentadoria para enfermeiras docentes que encontraram resultados semelhantes, mas que identificaram um sentimento de frustração e decepção pela falta de reconhecimento pelo que desenvolveram no tempo que estiveram no exercício da docência, aspecto não evidenciado no presente estudo.

Dessa forma, a aposentadoria é vista numa balança de ganhos e perdas. Os ganhos relacionados a um maior convívio familiar, lidar de forma diferente com o tempo, não ter que trabalhar sob pressão, ter tempo para lazer, viagens e amigos e cuidar de si. As perdas muitas vezes estão relacionadas à importância do trabalho e o sentimento de pertencimento do mesmo, ou aspectos macrossociais, como as questões econômicas e sociais que interferem na vida dos sujeitos.

\section{Conclusões}

De forma geral a aposentadoria foi representada de forma positiva pela maioria dos professores participantes. A aposentadoria apresenta-se como um evento da vida, embora não haja um planejamento para este momento, ele é tido como aguardado e bem-vindo, como um descanso necessário e merecido depois de um tempo muito grande de trabalho.

A relação familiar se apresenta essencial nessa nova fase, são os núcleos familiares que fazem com que este momento seja vivenciado de forma bem-sucedida ou não. A opção pelo não trabalho ou por continuar em alguma outra atividade é permeado pelo paradoxo entre o medo do ócio, a necessidade de se sentir útil e a necessidade de manutenção financeira da família, o que vem corroborar com as pesquisas realizadas com esse público.

Destaca-se ainda a necessidade de se mostrar útil socialmente e de como as relações construídas no trabalho são edificantes para a compreensão de uma aposentadoria bemsucedida. Dessa forma, compreende-se que aposentadoria e trabalho são visto de formas associadas quando as pessoas ainda se encontram na ativa. O trabalho dos professores 
universitários, no caso dessa pesquisa, traz a particularidade de ser também uma profissão de grande força social com muitas representações positivas associadas.

A principal representação da aposentadoria para este público foi associada a uma visão de uma nova etapa de vida. Mas, há também a representação de retorno à família, possibilidade de se fazer viagens e atividades de lazer, cuidados com saúde e família. A aposentadoria também aparece com algo a ser adiado diante a realidade social e econômica, assim como a forte identificação e satisfação com o trabalho.

Não houve diferença de representações entre as instituições pesquisadas, mostrando que de certa forma há uma homogeneização das representações dentro dessa classe profissional. Além disso, as diferenças mais marcantes foram entre os tempos de instituições e o sexo conforme pontuamos nas discussões.

Torna-se válido ressaltar que o presente estudo possui limitações. Compreendemos que novos estudos devem buscar relacionar as representações sociais e o adiamento da aposentadoria entre professores de diferentes contextos de ensino (superior, médio, fundamental), considerando o tipo de instituição (pública ou privada). Identificamos, portanto, uma agenda de pesquisa que evidencia a necessidade de estudos sobre trabalhadores mais velhos, relações intergeracionais no trabalho, relações entre as dimensões família e trabalho no processo decisório de aposentadoria.

Esse trabalho demonstrou que os professores não se preparam antecipadamente para este momento da vida, mesmo quando reconhecem a necessidade de pensar sobre a aposentadoria. Por conta disso, é fundamental que a discussão sobre a aposentadoria seja abordada nas universidades estimulando a participação de professores que estejam, pelo menos, a cinco anos do evento da aposentadoria.

\section{Referências}

Bosi, E. (1994). Memória e sociedade: lembranças de velhos. São Paulo: Companhia das letras.

Bressan, M. A. L. C., Mafra, S. C. T., França, L. H. F. P., Melo, M. S. S. \& Loreto, M. D. S. (2012). Trabalho versus Aposentadoria: desvendando sentidos e significados. Oikos: Revista Brasileira de Economia Doméstica, 23(1), 226-250.

Bressan, M. A., Mafra, S. C. T., França, L. H. F. P., Melo, M. S. S., \& Loreto, M. D. S. (2012). Trabalho versus aposentadoria: Desvendando sentidos e significados. Oikos: Revista Brasileira de Economia Doméstica, 23(1), 226-250.

Camargo, B. V. \& Justo, A. M. (2013). IRAMUTEQ: Um software gratuito para análise de dados textuais. Temas em Psicologia, 21(2), 513-518.

Carlos, S. A., Jacques, M. G. C., Larratéa, S.V., \& Heredia, O.C. (1999). Identidade, aposentadoria e terceira idade. Estudos Interdisciplinares sobre o Envelhecimento, 1, 77-89.

Cintra, T. S., \& De Figueiredo Ribeiro, D. (2009). Trabalho e aposentadoria: realidade social de moradores de um bairro periférico de uma cidade do interior de São Paulo. XV Encontro Nacional Da ABRAPSOPsicologia Social E Políticas De Existência: Fronteiras E Conflitos, 15.

Cintra, T. S., Ribeiro, D. F. \& Andrade, A. S. (2010). O cotidiano de aposentados que continuam trabalhando de maneira informal na indústria calçadista: percepções sobre a aposentadoria e o trabalho atual. Cadernos de Psicologia Social do Trabalho, 13(2), 277-287.

Costa, G. M. S; Barbosa, M. \& Vilas Boas, J. B de O. (2012). A percepção de trabalhadores e aposentados sobre as perdas e ganhos da aposentadoria. Revista Kaleidoscópio. Minas Gerais. v. 3, p. 01-18, Fev/Jun. 
Recuperado de:

http://www.unilestemg.br/kaleidoscopio/artigos/volume3/percepcao_de_trabalhadores.pdf

Denton, F. T., \& Spencer, B. G. (2009). What is retirement? A review and assessment of alternative concepts and measures. Canadian journal on aging/ La revue canadienne du vieillissement, 28(1), 63-76. Doi:10.1017/\$0714980809090047.

Instituto Brasileiro de Geografia e Estatística - IBGE. (2013). Projeção da população do Brasil por sexo e idade para o período 1980-2050 (Estudos \& Pesquisas-Informação Demográfica e Socioeconômica, No. 24). Recuperado de http://www.ibge.gov.br/home/estatistica/populacao/projecao_da_populacao/2013/projecao.pdf.

França, L. H. F. P \& Sandoval, L. A. N. (2014). Relacionamentos Familiares e conjugais na aposentadoria. In: S.G. Murta et al. Educação para aposentadoria: promoção de saúde e desenvolvimento na administração pública federal (1å. ed., pp. 68-82). Brasília: CEAD/FUB.

França, L. H. F. P, Menezes, G. S, Bendassolli, P. F., \& Macedo, L. S. S. (2013). Aposentar-se ou continuar trabalhando? O que influencia essa decisão? Psicologia: Ciência e Profissão, 33(3), 548-563. DOI: https://dx.doi.org/10.1590/S1414-98932013000300004.

França, L. H. F.P. \& Soares, D. H. P. (2009). Preparação para a aposentadoria como parte da educação ao longo da vida. Psicologia: Ciência e Profissão, 29(4), 738-751.

França, L. H. F. P.; Menezes, G. S. \& Siqueira, A. R. (2012) Planejamento para a aposentadoria: a visão dos garis. Revista Brasileira de Geriatria e Gerontologia, 15(4), 733-745.

França, L. (2008). O desafio da aposentadoria: o exemplo de executivos do Brasil e da Nova Zelândia. Rio de Janeiro: Rocco.

França, L. (2009). Influências sociais nas atitudes dos 'Top' executivos em face da aposentadoria: Um estudo transcultural. Revista de Administração Contemporânea, 13(1), 17-35. Recuperado de http://www.scientificcircle.com/pt/16963/influenciassociais-atitudes-top-executivos-face-estudo/

França, L. H. F. P., \& Carneiro, V. L. (2009). Programas de preparação para a aposentadoria: Um estudo com trabalhadores mais velhos em Resende (RJ). Revista Brasileira de Geriatria e Gerontologia, 12(3), 429447.

Jodelet, D. (2001). Representações sociais: um domínio em expansão. In: D. Jodelet (org.). As representações sociais. (pp. 17-44). Rio de Janeiro: EdUERJ.

Liberatti, V., Martins, J., Robazzi, M., Cardelli, A., Gvozd, R., \& Trevisan, G. (2015). Social representations of retirement for nurses teaching at one public university. Journal of Nursing UFPE. On Line JNUOL. DOI: 10.5205/01012007. Recuperado de http://www.revista.ufpe.br/revistaenfermagem/index.php/revista/article/view/7467.

Lima, M. S. C. (2012). Imagem e identidade: estudo sobre o professor universitário. Tese de Doutorado, Repositório da Universidade de Lisboa, Portugal.

Macêdo, L. S. S. (2014). Adiamento da aposentadoria e o significado do trabalho para servidores de uma universidade federal. Dissertação de Mestrado, Universidade Federal do Rio Grande do Norte. Natal, RN.

Macêdo, L. S. S., Bendassolli, P. F. \& Torres, T. L. (2017). Representações sociais da aposentadoria e intenção de continuar trabalhando. Psicologia \& Sociedade, 29, e145010, 1-11.

Magalhães, M. de O., Krieger, D. V., Straliotto, M. C. S \& Poeta, M. P. (2004). Padrões de ajustamento na aposentadoria. Revista Aletheia, 19, 57-68.

Menezes, G. S., \& França, L. H. (2012). Preditores da decisão da aposentadoria por servidores públicos federais. Revista Psicologia Organizações e Trabalho - RPOT, 12(3), 315-328.

Moscovici, S. (1978). A representação social da psicanálise. Rio de Janeiro: Zahar.

(2012). Representações Sociais: investigações em psicologia social. Tradução: Pedrinho A. Guareschi. 9a. ed. Petrópolis, Rio de Janeiro: Vozes.

Mutombo, E. (2013). 10 years of DG ENV IA's: A bird's-eye view on the EC environmental policy framing. ICPP 2013. 1st International Conference on Public Policy, Grenoble, France, 26-28. 
Nascimento, A.R.A., \& Menandro, P. R. M. (2006). Análise lexical e análise de conteúdo: Uma proposta de utilização conjugada. Estudos e Pesquisas em Psicologia, 6(2), 72-88.

Organização Mundial da Saúde (World Health Organization). (2005). Envelhecimento ativo: uma política de saúde. World Health Organization (OMS); tradução Suzana Gontijo. - Brasília: Organização PanAmericana da Saúde.

Roesler, V., \& Soares, D. H. P. (2010, junho). O que é aposentadoria? Morte social culpa e constrangimento ou dever cumprido, prazer e liberdade? Comunicação apresentada na I Jornada Internacional de práticas clínicas no campo social, Maringá. ANAIS da Editora da Universidade de Maringá. Acessado em: http://www.ppi.uem.br/camposocial/eventos/i_jornada/049.pdf

Shultz, K. S., \& Wang, M. (2011). Psychological perspectives on the changing nature of retirement. The American psychologist, 66(3), 170-9. doi:10.1037/a0022411.

Stano, R. C. M. T. (2001). Identidade do professor no envelhecimento. São Paulo: Cortez.

Veloz, M. C. T., Nascimento-Schulze, C. M., \& Camargo, B. V. (1999). Representações sociais do envelhecimento. Psicologia Reflexão \& Crítica, 12(2), 479-501.

Wachelke, J. F. R., Camargo, B. V., Hazan, J. V., Soares, D. R., Oliveira, L. T.P., \& Reynaud, P.D. (2008). Princípios organizadores da representação social do envelhecimento: dados coletados via internet. Estudos de Psicologia, 13(2), 107-116.

Zanelli, J. C; Silva, N. \& Soares, D. H. P. (2010). Orientações para aposentadoria nas organizações de trabalho: construção de projetos para pós-carreira. Porto Alegre: ARTMED.

Apresentação: 30/06/2016

Aprovação: 15/12/2017 